CLINICAL STUDY

\title{
Soluble $\alpha$-Klotho: a novel serum biomarker for the activity of GH-producing pituitary adenomas
}

\author{
Marian Christoph Neidert, Lisa Sze ${ }^{1,2}$, Cornelia Zwimpfer ${ }^{1}$, Johannes Sarnthein, Burkhardt Seifert ${ }^{3}$, \\ Karl Frei, Henning Leske ${ }^{4}$, Elisabeth Jane Rushing ${ }^{4}$, Christoph Schmid ${ }^{1}$ and René-Ludwig Bernays \\ Department of Neurosurgery, University Hospital Zurich, University of Zurich, Frauenklinikstrasse 10, CH-8091 Zurich, Switzerland, ${ }^{1}$ Division of \\ Endocrinology and Diabetes, University Hospital Zurich, University of Zurich, Rämistrasse 100, CH-8091 Zurich, Switzerland, ${ }^{2}$ Division of Endocrinology \\ and Diabetes, Kantonsspital St Gallen, Rorschacherstraße 95, CH-9007, St Gallen, Switzerland, ${ }^{3}$ Division of Biostatistics, Institute for Social and \\ Preventive Medicine, University of Zurich, Hirschengraben 84, CH-8001 Zurich, Switzerland and ${ }^{4}$ Department of Neuropathology, University Hospital \\ Zurich, University of Zurich, Schmelzbergstrasse 12, CH-8091 Zurich, Switzerland
}

(Correspondence should be addressed to M C Neidert; Email: marian.neidert@usz.ch)

\begin{abstract}
Objective: Klotho is a lifespan-influencing gene expressed mainly in the kidneys. Soluble $\alpha$-Klotho ( $\alpha \mathrm{KL})$ is released into the circulation. In this study, we present baseline $\alpha \mathrm{KL}$ serum levels of patients with acromegaly compared with controls with other pituitary adenomas and assess changes following transsphenoidal surgery.

Design: Prospective controlled study.

Methods: We measured soluble $\alpha$ KL (sandwich ELISA) and IGF1 (RIA) in sera of 14 patients (eight females and six males) with active acromegaly and in 22 control patients (13 females and nine males) operated for non-GH-producing pituitary adenomas. Immunohistochemical staining for Klotho was performed in resected adenomas and in normal pituitary tissue samples.

Results: Soluble $\alpha \mathrm{KL}$ was high in the acromegaly group preoperatively (median $4217 \mathrm{pg} / \mathrm{ml}$, interquartile range (IQR) 1812-6623 pg/ml) and declined after surgery during early follow-up (2-6 days; median $645 \mathrm{pg} / \mathrm{ml}$, IQR 550-1303 pg/ml) $(P<0.001)$ and during late follow-up $(2-3$ months post-operatively; median $902 \mathrm{pg} / \mathrm{ml}$, IQR $497-1340 \mathrm{pg} / \mathrm{ml} ; P<0.001)$. In controls, preoperative soluble $\alpha$ KL was significantly lower than in acromegalics, $532 \mathrm{pg} / \mathrm{ml}(400-677 \mathrm{pg} / \mathrm{ml}$; $P<0.001)$. Following surgery, soluble $\alpha$ KL remained low during early and late follow-up - changes over time within the control group were not statistically significant. These results were independent of age, sex and kidney function. Klotho staining was equal or slightly decreased in GH-positive adenomas compared with controls.

Conclusion: High soluble $\alpha \mathrm{KL}$ serum levels were specific to GH-producing adenomas and decreased rapidly following adenoma removal. Thus, soluble $\alpha \mathrm{KL}$ appears to be a new specific and sensitive biomarker reflecting disease activity in acromegaly. Similar Klotho staining patterns in controls and acromegalics suggest that the rise in serum $\alpha$ KL is caused by systemic actions of pituitary GH rather than due to increased expression of Klotho by the pituitary (adenoma).
\end{abstract}

European Journal of Endocrinology 168 575-583

\section{Introduction}

The $\alpha$-klotho gene $(\alpha K l)$ was serendipitously discovered as a lifespan-influencing gene in mice after recognition that its disruption caused accelerated ageing (1). Lifespan extension was achieved by overexpression (2). In humans, variants of $\alpha K L$ were associated with ageing (3) and the phenotype of a rare homozygous missense mutation was described (4). The gene and protein were named after the Greek goddess Klotho who spins the thread of life. $\alpha K l$ encodes $\alpha$ KL protein, a $130 \mathrm{kDa}$ type I membrane protein (1014 amino acids long) considered the founder of the Klotho family that is predominantly expressed in the kidneys, choroid plexus and several endocrine organs including the pituitary, parathyroid, testis, ovary, placenta and pancreas (1). The $\alpha \mathrm{KL}$ protein exists in two forms with distinct functions. Membrane-bound $\alpha \mathrm{KL}$ is a co-receptor for fibroblast growth factor 23, a bone-derived phosphaturic hormone that inhibits renal phosphate reabsorption and calcitriol production $(5,6)$. Soluble $\alpha \mathrm{KL}$ attenuates insulin/insulin-like growth factor 1 (IGF1) signalling and regulates calcium homoeostasis $(7,8)$. The extracellular domain of the membrane-bound form can be enzymatically cleaved (ectodomain shedding) and released as soluble $\alpha \mathrm{KL}$ into blood, urine and cerebrospinal fluid $(9,10)$. Recently, a sandwich ELISA for the measurement of soluble $\alpha \mathrm{KL}$ was established and is now commercially available (11). Soluble $\alpha \mathrm{KL}$ was inversely related to age in healthy subjects (11) and 
with mortality in the elderly (12). High levels of soluble aKL were found in human umbilical cord blood (13), and based on a positive correlation between plasma levels of soluble $\alpha \mathrm{KL}$ and growth and metabolic parameters in premature and term neonates, it has been speculated that Klotho may play a role in the stimulation of growth (14).

GH excess due to benign adenomas of the pituitary gland is the major cause for acromegaly with an incidence of approximately four cases per 1 million persons per year (15). Acromegaly is usually diagnosed with a considerable delay and therefore possibly associated with increased mortality even after curative transsphenoidal surgery (16). Clinical features develop slowly over many years and comprise metabolic derangements and pathognomonic changes in the patient's appearance, mainly soft tissue swelling and skeletal bone growth, resulting in typical acral enlargement and coarse facial features. Metabolic changes include increased plasma glucose in the wake of insulin resistance despite reduced visceral fat and high levels of serum phosphate accompanied by higher than normal renal glomerular filtration $(17,18,19)$. Both insulin resistance and elevated serum phosphate are associated with increased mortality in the general population $(20,21)$. In the setting of reduced visceral fat and increased glomerular filtration, insulin resistance and serum phosphate elevation are unusual, and the underlying mechanisms are unclear. Currently, GH (the hormone directly produced by the adenoma) and IGF1 (a GH-dependent, predominantly liver-derived hormone) are the classical biochemical markers of disease activity in acromegaly.

We recently found that serum-soluble $\alpha \mathrm{KL}$ is markedly elevated in patients with acromegaly and that this $\alpha \mathrm{KL}$ excess reversed following adenoma removal (22). In order to assess whether high serum levels of soluble $\alpha \mathrm{KL}$ are specific to patients with GH-producing pituitary adenomas, we now present a prospective controlled study that documents the baseline serum levels of $\alpha \mathrm{KL}$ in patients with acromegaly compared with a control group of patients with other pituitary adenomas. Additionally, we monitor the temporal changes in $\alpha \mathrm{KL}$ levels following transsphenoidal surgery, and we report detailed immunohistochemical analysis of the adenomas removed.

\section{Materials and methods}

\section{Patient characteristics}

We included 14 consecutive patients with active acromegaly (eight females and six males) with a mean age of 48 years (range 29-84 years) who underwent transsphenoidal surgery at the University Hospital Zurich. The preoperative diagnosis of acromegaly was based on pathognomonic clinical findings and biochemical markers (excess IGF 1 and GH, nonsuppressible during a $75 \mathrm{~g}$ oral glucose tolerance test (oGTT)). Patients were excluded when histopathological examination failed to identify a GH-producing adenoma. As a control group, we included 22 patients (13 females and nine males) with a mean age of 48 years (range 14-81 years) operated for pituitary adenomas not producing GH (13 non-functioning adenomas (NFAs) and nine prolactinomas). All patients provided written informed consent and the study was approved by the Local Ethics Committee. Detailed patient characteristics are summarized in Tables 1 and 2. Tumour volume calculation was based on preoperative magnetic resonance imaging (MRI) and the diameter method (tumour volume $=$ $4 / 3 \times p \times 1 / 2 x \times 1 / 2 y \times 1 / 2 z$ ), where $x, y$ and $z$ are the maximum diameters within the three axes. Surgical strategy was transnasal transsphenoidal using microsurgical technique and intraoperative MRI (PoleStar N20, 0.15T, Medtronic Navigation, Minneapolis, MN, USA). All procedures were performed by the senior author (R-L Bernays) - details on the surgical strategy have been described previously (23).

\section{Histopathology}

All pathology materials, consisting of H\&E and reticulin-stained sections, a full panel of anterior pituitary hormone immunohistochemistry, and the MIB-1 (Ki-67) proliferation marker were reviewed to confirm the diagnosis. Pituitary adenomas were then categorized as either GH-positive adenomas, adenomas without hormone expression (NFAs) or prolactinomas.

GH antibodies were obtained from Thermo scientific (Waltham, MA, USA; MA5-11926, 1:3000) and Klotho antibodies were purchased from Abcam (Cambridge, UK; ab68208, 1:40). Immunophenotypic analysis was performed using a Leica Bond-Max automated immunostainer employing $2 \mu \mathrm{m}$-thick, formalin-fixed, paraffin-embedded sections. GH signal detection was performed using 3,3'-diaminobenzidin (brown) and 3-amino-9-ethylcarbazole (red) for Klotho detection respectively. Sections were counterstained with haematoxylin. For co-localization analysis, the sections were treated with citric acid for $15 \mathrm{~min}$ at $95^{\circ} \mathrm{C}$ and immunofluorescent co-stainings were performed according to the Bond staining protocol. GH-positive areas were detected using the secondary antibody Alexa 488 anti-mouse (1:1000) and Alexa 594 anti-rabbit antibody (1:1000) for Klotho signals respectively.

\section{Assays}

All blood samples were drawn around the same time in the morning after overnight fasting. Soluble $\alpha$ KL was determined using a sandwich ELISA described by Yamazaki et al. (11) (Kyowa Hakko Kirin Co. Ltd., Tokyo, Japan) according to the manufacturer's instructions. IGF1 was measured by RIA after the removal of carrier proteins as described elsewhere (22) and 
Table 1 (A) Patient characteristics of the acromegaly group $(n=14)$; immunohistological reactivity to other hormones than GH is shown in parentheses. (B) Patient characteristics of the control group $(n=22)$; minor immunohistological hormonal reactivity is shown in parentheses. Preoperative GH, $\alpha$-Klotho and IGF1 serum levels in controls with minor GH positivity were within the normal range (see Supplementary Table 1, see section on supplementary data given at the end of this article) and the latter two markers did not show the post-operative decrease characteristic for the acromegaly group.

\begin{tabular}{|c|c|c|c|c|c|c|}
\hline Case & Age & Sex & Staining & $\begin{array}{c}\text { Tumour } \\
\text { volume }\left(\mathrm{mm}^{3}\right)\end{array}$ & BMI $\left(\mathrm{kg} / \mathrm{m}^{2}\right)$ & $\begin{array}{c}\text { Preoperative } \\
\text { GFR }(\mathrm{ml} / \mathrm{min} \text { per } \\
\left.1.73 \mathrm{~m}^{2}\right)\end{array}$ \\
\hline \multicolumn{7}{|c|}{ (A) Patient characteristics of the acromegaly group } \\
\hline 1 & 43 & $\mathrm{M}$ & $\mathrm{GH}++$ & 880 & 29.2 & 106 \\
\hline 2 & 30 & $\mathrm{~F}$ & $\mathrm{GH}++(\mathrm{PRL}+)$ & 2492 & 25.7 & 120 \\
\hline 3 & 54 & $\mathrm{M}$ & $\mathrm{GH}++$ & 576 & 27.8 & 97 \\
\hline 4 & 84 & $\mathrm{M}$ & $\mathrm{GH}++(\mathrm{PRL}+)$ & 4775 & 28.6 & 59 \\
\hline 5 & 40 & $\mathrm{~F}$ & $\mathrm{GH}++(\mathrm{LH}+++, \mathrm{HCG}+)$ & 110 & 38.6 & 99 \\
\hline 6 & 41 & $\mathrm{~F}$ & $\mathrm{GH}++$ & 3541 & 24.6 & 118 \\
\hline 7 & 43 & $\mathrm{~F}$ & $\mathrm{GH}++(\mathrm{PRL}+)$ & 7948 & 23 & 113 \\
\hline 8 & 42 & $\mathrm{~F}$ & $\mathrm{GH}++$ & 1026 & 33.7 & 118 \\
\hline 9 & 53 & $\mathrm{~F}$ & $\mathrm{GH}++(\mathrm{PRL}+)$ & 286 & 32 & 104 \\
\hline 10 & 64 & $\mathrm{~F}$ & $\mathrm{GH}++$ & 3519 & 20.7 & 104 \\
\hline 11 & 52 & $\mathrm{M}$ & $\mathrm{GH}++$ & 1334 & 38.7 & 101 \\
\hline 12 & 42 & $\mathrm{~F}$ & $\mathrm{GH}++$ & 4524 & 24.5 & 97 \\
\hline 13 & 29 & $\mathrm{M}$ & $\mathrm{GH}++$ & 1634 & 33.7 & 127 \\
\hline 14 & 45 & $\mathrm{M}$ & $\mathrm{GH}++$ & 50 & 37.6 & 85 \\
\hline \multicolumn{7}{|c|}{ (B) Patient characteristics of the control group } \\
\hline 1 & 75 & $\mathrm{~F}$ & NFA & 5864 & 25 & 83 \\
\hline 2 & 29 & $\mathrm{~F}$ & $\mathrm{PRL}++(\mathrm{GH}+)$ & 280 & 20.4 & 129 \\
\hline 3 & 75 & $\mathrm{~F}$ & $\mathrm{NFA}(\mathrm{FSH}+)$ & 5483 & 22.9 & 89 \\
\hline 4 & 81 & M & NFA & 1021 & 31.7 & 82 \\
\hline 5 & 32 & $\mathrm{~F}$ & $\mathrm{PRL}++$ & 339 & 20.2 & 100 \\
\hline 6 & 49 & M & NFA & 11310 & 29.3 & 88 \\
\hline 7 & 39 & $\mathrm{M}$ & $\mathrm{NFA}(\mathrm{FSH}++, \mathrm{TSH}+)$ & 2714 & 23.2 & 96 \\
\hline 8 & 47 & $\mathrm{M}$ & NFA & 1407 & 22.2 & 100 \\
\hline 9 & 30 & $\mathrm{M}$ & NFA & 16085 & 27.5 & 123 \\
\hline 10 & 65 & $\mathrm{M}$ & $\mathrm{PRL}++$ & 8181 & 29.4 & 75 \\
\hline 11 & 14 & $\mathrm{~F}$ & $\mathrm{PRL}++$ & 2246 & 17.9 & 133 \\
\hline 12 & 61 & $\mathrm{~F}$ & $\mathrm{NFA}(\mathrm{GH}+, \mathrm{TSH}+)$ & 4516 & 27.3 & 94 \\
\hline 13 & 63 & $\mathrm{~F}$ & $\mathrm{PRL}++(\mathrm{GH}+)$ & 16118 & 28.7 & 79 \\
\hline 14 & 36 & $\mathrm{~F}$ & $\mathrm{PRL}++(\mathrm{ACTH}+, \mathrm{GH}+)$ & 403 & 26.6 & 76 \\
\hline 15 & 68 & $\mathrm{M}$ & NFA & 2368 & 27.5 & 72 \\
\hline 16 & 69 & $\mathrm{M}$ & NFA & 2356 & 34 & 48 \\
\hline 17 & 48 & $\mathrm{~F}$ & NFA & 628 & 20.2 & 109 \\
\hline 18 & 17 & M & $\mathrm{PRL}++$ & 377 & 21.9 & 129 \\
\hline 19 & 18 & $\mathrm{~F}$ & $\mathrm{PRL}++(\mathrm{GH}+)$ & 622 & 15.8 & 128 \\
\hline 20 & 57 & $\mathrm{~F}$ & $\mathrm{NFA}(\mathrm{LH}+)$ & 15683 & 19.7 & 101 \\
\hline 21 & 32 & $\mathrm{~F}$ & $\mathrm{PRL}++$ & 452 & 18.1 & 119 \\
\hline 22 & 54 & $\mathrm{~F}$ & NFA $(\mathrm{FSH}+)$ & 674 & 27.3 & 100 \\
\hline
\end{tabular}

GH by IRMA (hGH-RIATC; CIS Bio International, Oris Industries, Gif-Sur-Yvette, France). Creatinine was measured using the kinetic Jaffé method on a Roche COBAS 8000 analyzer (Roche Diagnostics) and glomerular filtration rate (GFR) was estimated using the Chronic Kidney Disease Epidemiology Collaboration (CKD-EPI) formula. These values were recorded as soluble $\alpha \mathrm{KL}$ is associated with renal function (11). Both soluble $\alpha \mathrm{KL}$ and IGF1 were measured preoperatively, at least once shortly after surgery (2-6 days post-operatively, before discharge) and again at the first outpatient follow-up (2-3 months after surgery). In all control patients and in a subgroup of seven acromegaly patients, multiple short-term post-operative measurements were performed. GH was measured preoperatively in all patients.

\section{Statistical analyses}

Statistical analyses were performed using commercially available software IBM SPSS Statistics 20 (SPSS, Inc.) and Matlab (www.mathworks.com). Continuous variables are presented as median with interquartile range (IQR). Preoperative variables were compared between groups using the Mann-Whitney $U$ test or the $\chi^{2}$ test as appropriate. The Wilcoxon signed-rank test was used for comparing pre- and post-operative values within one group. To corroborate the results of bivariate testing, we constructed a general linear model (GLM) for repeated measures. The dependent variable was soluble aKL after log-transformation. The within-subjects factor was time with the levels preoperative, early postoperative and late post-operative. Between-subjects 
Table 2 Group characteristics are presented as median and interquartile range (IQR).

\begin{tabular}{lccc}
\hline & Acromegaly $(n=14)$ & Control $(n=22)$ & $\boldsymbol{P}$ value \\
\hline Sex $(\mathrm{M} / \mathrm{F})$ & $6 / 8$ & $9 / 13$ & $0.91^{\mathrm{a}}$ \\
Age (years) & $43(41-53)$ & $49(31-66)$ & $0.79^{\mathrm{b}}$ \\
$\mathrm{BMI}\left(\mathrm{kg} / \mathrm{m}^{2}\right)$ & $28.9(24.6-34.7)$ & $24.1(20.2-27.8)$ & $0.010^{\mathrm{b}}$ \\
Preoperative GFR & $104(97-118)$ & $98(81.25-120)$ & $0.35^{\mathrm{b}}$ \\
$\quad\left(\mathrm{ml} / \mathrm{min}\right.$ per $\left.1.73 \mathrm{~m}^{2}\right)$ & & & \\
Preoperative GH $(\mathrm{ng} / \mathrm{ml})$ & $10.3(7.01-43.10)$ & $0.29(0.13-0.74)$ & $<0.001^{\mathrm{b}}$ \\
Tumour volume $\left(\mathrm{mm}^{3}\right)$ & $1483(503-3786)$ & $2301(579-6443)$ & $0.45^{\mathrm{b}}$ \\
Hospital stay $($ days $)$ & $6(5-7)$ & $6(5-7)$ & $0.60^{\mathrm{b}}$ \\
\hline a $\chi^{2}$ Test. & & & \\
b Mann-Whitney $U$ test. & & &
\end{tabular}

factors were group and sex, and covariates were age and preoperative GFR. Two-tailed $P$ values $<0.05$ were considered statistically significant.

\section{Results}

\section{Patient characteristics}

Both study groups, acromegalics (eight females and six males; mean age 48 years) and controls (13 females and nine males; mean age 49 years), had successful transsphenoidal removal (at least debulking) of their adenomas - detailed histopathological results are shown in Fig. 1. Within the group of patients with active acromegaly, median estimated tumour volume was $1484 \mathrm{~mm}^{3}$ (IQR 503-3786 $\mathrm{mm}^{3}$ ). Of all 14 acromegalic patients, two (14\%) patients presented with microadenomas, whereas $12(86 \%)$ presented with macroadenomas. In the control group $(n=22 ; 13$ females and nine males; 13 NFAs and nine prolactinomas; mean age of 49 years), median preoperative tumour volume was $2301 \mathrm{~mm}^{3}$ (580-6444 $\left.\mathrm{mm}^{3}\right)$. Microadenomas were seen in two cases $(9 \%)$. When preoperative tumour volume was compared between both groups, no statistical difference was identified $(P=0.45$, MannWhitney $U$ test).

\section{Soluble serum $\alpha K L$}

Soluble $\alpha \mathrm{KL}$ was high in the acromegaly group before surgery (Figs 1 and 2) with a soluble $\alpha \mathrm{KL}$ median of $4217 \mathrm{pg} / \mathrm{ml}$ (1813-6624 pg/ml), then levels declined after removal of the GH-producing adenoma to a median of $646 \mathrm{pg} / \mathrm{ml}(550-1303 \mathrm{pg} / \mathrm{ml}) \quad(P<0.001$, Wilcoxon signed-rank test) during early follow-up (2-6 days post-operatively), then to a median of $902 \mathrm{pg} / \mathrm{ml}(498-1341 \mathrm{pg} / \mathrm{ml} ; P<0.001)$ during late follow-up (2-3 months post-operatively) - soluble $\alpha \mathrm{KL}$ kinetics are shown in Fig. 1. Compared with acromegalics, the preoperative median of soluble $\alpha \mathrm{KL}$ in controls was significantly lower, $532 \mathrm{pg} / \mathrm{ml}$ (400$678 \mathrm{pg} / \mathrm{ml} ; \mathrm{P}<0.001)$. Following surgery, soluble $\alpha \mathrm{KL}$ stayed low with $404 \mathrm{pg} / \mathrm{ml}$ (320-635 pg/ml) during early follow-up and $524 \mathrm{pg} / \mathrm{ml}$ (359-621 pg/ml) during late follow-up - changes over time within the control group were not statistically significant. The relative drop of soluble $\alpha \mathrm{KL}$ (early follow-up/preoperative) was more pronounced in the acromegaly group, 0.25 (range 0.1-0.5) compared with controls, 0.95 (range 0.5-1.6) $(P<0.001)$. Short-term kinetics of $\alpha \mathrm{KL}$ levels of individual acromegalic patients compared with controls is plotted in Fig. 2A. To corroborate the results of bivariate testing, we constructed a GLM for repeated measures after log-transformation of our data. The only significant interaction was found between TIME and GROUP ( $F=33$, hypothesis degrees of freedom (df) 2 , error df $17, P<0.001)$ - the temporal changes of the two groups on a log-scale are not parallel. Group differences and significant post-operative decrease in the acromegaly group concerning soluble $\alpha \mathrm{KL}$ levels were independent of age, sex and kidney function (GFR).

\section{IGF 1}

As expected, preoperative median IGF1 levels were higher in the acromegaly group, $483 \mathrm{ng} / \mathrm{ml}$ $(367-640 \mathrm{ng} / \mathrm{ml})$ compared with the control group, $86 \mathrm{ng} / \mathrm{ml} \quad(53-136 \mathrm{ng} / \mathrm{ml}) \quad(P<0.001)$. Within the acromegaly group, median preoperative IGF1 levels of $483 \mathrm{ng} / \mathrm{ml}$ returned to median early post-operative (2-6 days post-operatively) IGF1 levels of $182 \mathrm{ng} / \mathrm{ml}$ (144-229 ng/ml; $P<0.001)$, whereas no significant difference was found between preoperative and postoperative IGF1 levels within the control group. The long-term IGF1 time course within the acromegaly group (Fig. 1A) and controls (Fig. 2A) is illustrated in Fig. 1. The short-term time course of IGF1 levels of individual acromegalic patients compared with controls are plotted in Fig. 2B.

\section{GH}

Preoperative GH levels were significantly higher in the acromegaly group as expected $(P<0.001)$. In all acromegalic patients, surgery resulted in a significant decrease in $\mathrm{GH}$ with median preoperative levels of $10 \mathrm{ng} / \mathrm{ml}(7-43 \mathrm{ng} / \mathrm{ml})$ and median post-operative values of $1.9 \mathrm{ng} / \mathrm{ml}(0.6-2.5 \mathrm{ng} / \mathrm{ml})(P<0.001)$ and 

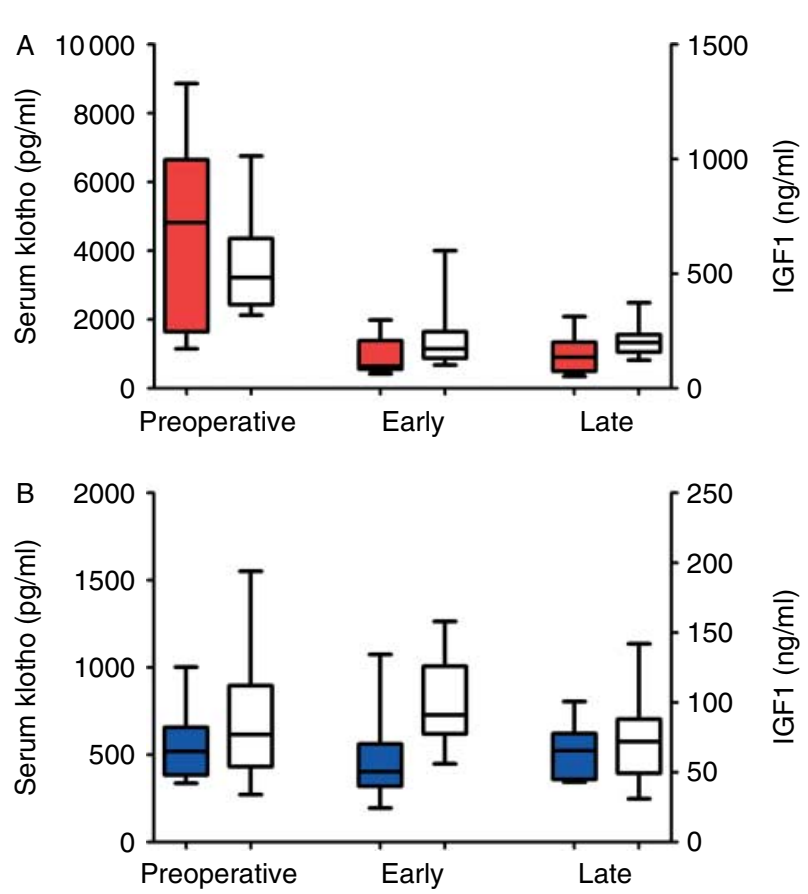

Figure 1 Time course of serum-soluble $\alpha$-Klotho in acromegalics (A, red boxes $(n=12))$ and controls $(\mathrm{B}$, blue boxes $(n=12))$ and IGF1 (white boxes) in both groups. Preoperative, early (2-6 days post-operatively, at discharge from hospital) and late (2-3 months post-operatively) follow-up values are plotted. Note the different scales in (A) and (B).

disease features improved as judged by all patients and treating physicians. Median preoperative $\mathrm{GH}$ levels in the control group were $0.3 \mathrm{ng} / \mathrm{ml}(0.1-0.7 \mathrm{ng} / \mathrm{ml})-$ post-operative measurements of $\mathrm{GH}$ were only performed in the acromegaly group. The covariation of soluble $\alpha$ KL, IGF1 and GH is shown in Supplementary Figure 1, see section on supplementary data given at the end of this article.

\section{BMI and kidney function}

BMI was significantly higher in the acromegaly group $(P=0.010)$ with a median BMI of $28.9 \mathrm{~kg} / \mathrm{m}^{2}$ $\left(24.6-34.7 \mathrm{~kg} / \mathrm{m}^{2}\right)$ compared with a median BMI of $24.1 \mathrm{~kg} / \mathrm{m}^{2}\left(20.2-27.8 \mathrm{~kg} / \mathrm{m}^{2}\right)$ in the control group. In terms of preoperative kidney function, there was no significant difference regarding preoperative GFR $(P=0.35)$ with a median preoperative GFR of $104 \mathrm{ml} /$ min per $1.73 \mathrm{~m}^{2}\left(97-118 \mathrm{ml} / \mathrm{min}\right.$ per $\left.1.73 \mathrm{~m}^{2}\right)$ and $98 \mathrm{ml} / \mathrm{min}$ per $1.73 \mathrm{~m}^{2}(81.25-120 \mathrm{ml} / \mathrm{min}$ per $1.73 \mathrm{~m}^{2}$ ) in acromegalics and in controls respectively. However, distinct changes were observed in response to surgery: post-operative GFR decreased in patients undergoing transsphenoidal surgery for GH-producing adenomas, median $\triangle$ GFR (post-operative GFRpreoperative GFR) was $-4.50 \mathrm{ml} / \mathrm{min}$ per $1.73 \mathrm{~m}^{2}$ $\left(-9.00\right.$ to $-0.75 \mathrm{ml} / \mathrm{min}$ per $\left.1.73 \mathrm{~m}^{2}\right)$, whereas GFR increased in controls with a median $\triangle G F R$ of
$6.50 \mathrm{ml} / \mathrm{min}$ per $1.73 \mathrm{~m}^{2}(3.50-11.50 \mathrm{ml} / \mathrm{min}$ per $\left.1.73 \mathrm{~m}^{2}\right) \quad(P<0.001)$. The difference between preoperative and post-operative GFR was statistically significant in both acromegalics $(P=0.006)$ and controls $(P=0.001)$.

\section{Immunohistochemistry}

GH-producing adenomas (Fig. 3A, B and C) showed variable GH expression within the tumour (brown) from samples with strong, diffuse immunoreactivity to those with weaker and/or focal paranuclear staining. These staining patterns corresponded to either densely or sparsely granulated subtypes. In cases with focal or weak GH staining, effacement of the normal lobular architecture confirmed the presence of tumour. The Klotho expression pattern (red) in corresponding areas was more diffuse and independent of GH-positive cells. The cells in the GH-negative control group, consisting of hormone-inactive pituitary adenomas (Fig. 3D and E), and a prolactinoma (Fig. 3F) showed diffuse and strong positivity for Klotho. There is no stringent
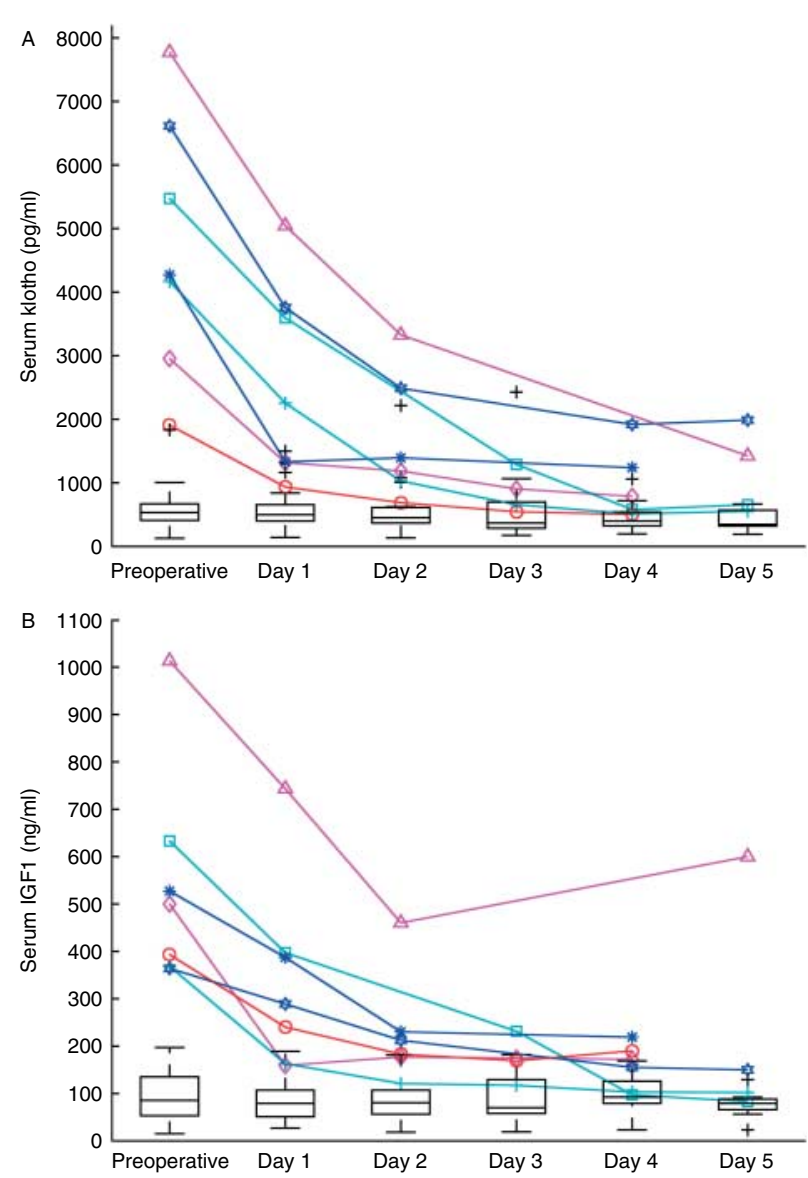

Figure 2 Individual short-term time course of soluble $\alpha$-Klotho (A) and IGF1 (B) in acromegaly patients $(n=7)$ (coloured lines) compared with box-plots of all control patients. 

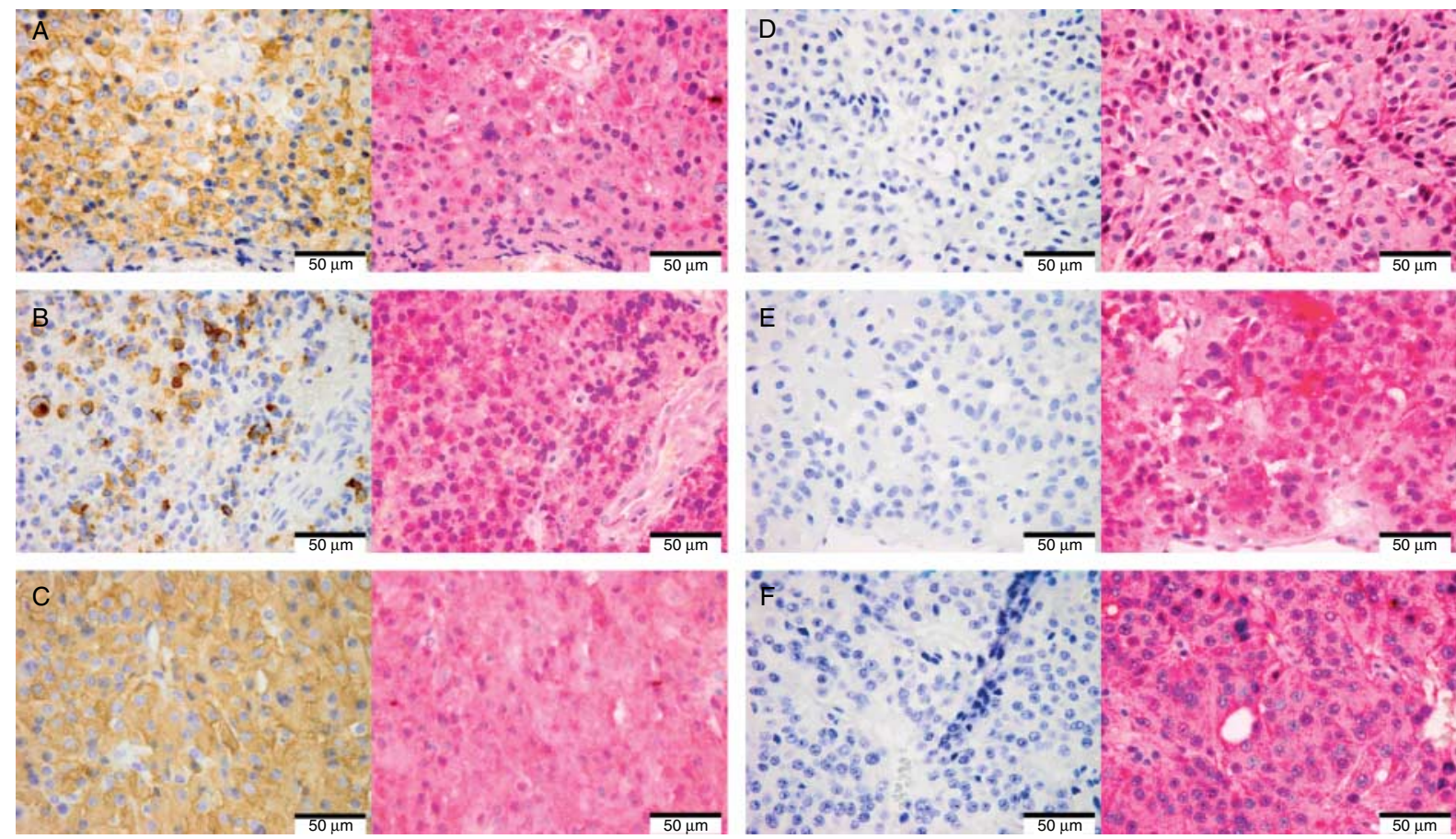

Figure 3 Klotho expression in GH-producing adenomas vs the control group. Three examples of GH-producing adenomas (A, case 11; B, case 7 and C, case 8) with GH expression (brown) and diffuse Klotho expression (red) are depicted in corresponding areas. In the control group, hormone-inactive pituitary adenomas (D, case 1 and E, case 4$)$ and a prolactinoma (F, case 10) lack GH positivity. Klotho expression seems to be equal or slightly increased in the control compared with GH-positive adenomas. Original magnification $400 \times$.

co-localization of these two markers. Immunofluorescence analysis (Fig. 4) emphasizes that Klotho (Alexa 594 , red) is independently expressed from GH-positive cells (Alexa 488, green). Original magnification $400 \times$. Klotho and GH staining in normal pituitary is shown in Fig. 5.

\section{Discussion}

This is the first prospective controlled study that documents serum levels of $\alpha \mathrm{KL}$ in patients with active acromegaly compared with a control group of patients with other pituitary adenomas. Moreover, we monitored $\alpha \mathrm{KL}$ levels over time (short- and long-term follow-up) following transsphenoidal surgery. Our results show a highly significant difference in preoperative $\alpha \mathrm{KL}$ levels between acromegalics and controls, indicating that $\alpha \mathrm{KL}$ excess is specific for GH-positive adenomas. Reversal of aKL occurs rapidly after surgery and there are no significant differences between short- and long-term follow-up, suggesting that $\alpha \mathrm{KL}$ is a very sensitive marker for disease activity of acromegaly. Both the preoperative group difference and the rapid post-operative decrease in $\alpha$ KL levels in acromegalics remained significant after adjusting our results for age, sex and kidney function. The mechanisms leading to soluble $\alpha \mathrm{KL}$ excess in the serum in active acromegaly remain unclear. Soluble $\alpha \mathrm{KL}$ could arise either from a distinct transcript (24) or from ectodomain shedding of membrane Klotho $(9,10,25)$. It remains unclear whether in acromegalics membraneassociated Klotho (mainly found in the kidneys) and soluble $\alpha \mathrm{KL}$ (as detected in the serum) rise concurrently or whether elevated soluble $\alpha \mathrm{KL}$ is unrelated or possibly inversely related to the abundance of plasma membrane Klotho in the kidneys - possibly resulting from enhanced enzymatic activity. Admittedly, we cannot provide our own experimental data to support this favoured hypothesis. aKL (130 kDa) appears to result from proteolytic ectodomain clipping (10). Two members of the 'A Disintegrin and Metalloproteinase' (ADAM) family, ADAM10 and ADAM17, have been suggested as the responsible enzymes (9), and the activity of secretases $(25,26)$ shedding the ectodomain from the integral membrane Klotho may be increased in acromegaly, either directly by GH or indirectly by factors or a proteolytic activity induced by $\mathrm{GH}$.

For obvious reasons, renal biopsies to check for changes in membrane-bound Klotho abundance were not feasible in our study population. However, we analysed Klotho staining in GH-producing adenomas, in controls (NFAs and prolactinomas) and in normal pituitary tissue samples. The immunohistochemical staining pattern presented suggests that the rise in serum $\alpha \mathrm{KL}$ is not explained by increased pituitary (adenoma) Klotho expression but rather due to an increase in pituitary GH secretion. 


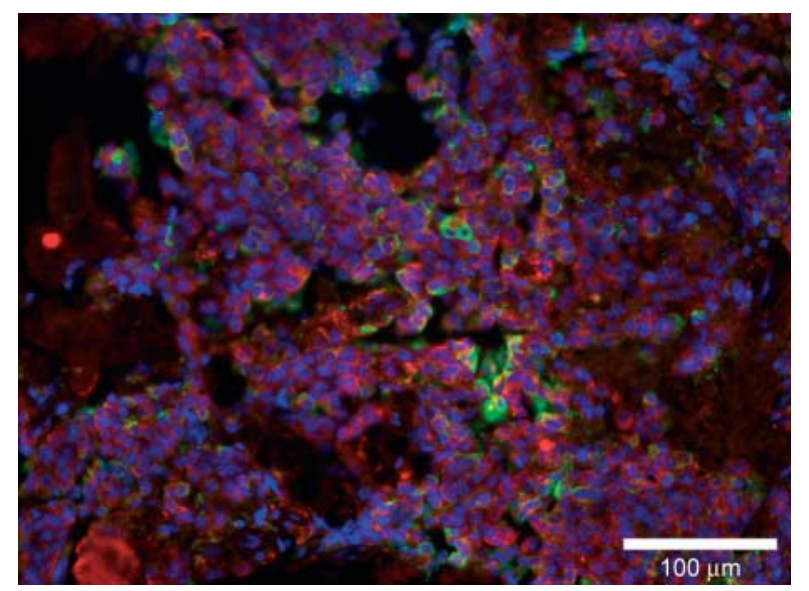

Figure 4 Immunofluorescence of a GH-positive adenoma showing GH-positive cells (Alexa 488, green) and diffuse positivity for Klotho (Alexa 594, red). Nuclear counterstain with Dapi (blue). Original magnification $100 \times$.

Until now, GH (a hormone produced by the adenoma itself) and especially IGF1 (a GH-stimulated, predominantly liver-derived peptide) have been the 'classical' biomarkers for diagnosing and monitoring disease activity during the treatment of patients with acromegaly. In fact, their normalization has been linked to decreased mortality $(27,28,29)$. However, it has been recognized that both parameters entail various shortcomings.

Serum levels of IGF1 are influenced not only by GH status but also by age, moreover, by gender (estrogens), race, genetic makeup, liver function, nutritional status, portal insulin, thyroid hormones and by concomitant inflammatory disease. Some of these influences, particularly the former, may also have an impact on $\alpha \mathrm{KL}$ (to an as yet unknown extent). Serum IGF1 is mainly derived from the liver and tightly bound to IGF binding proteins (IGFBPs) $(30,31)$. Changes in IGFBP concentrations contribute to the limitations known for a variety of IGF1 assays (32). To circumvent these problems, we used a classical and time-consuming assay in which carrier proteins are removed before the samples are incubated with the antibodies $(33,34)$.

Dynamic testing using oGTT to suppress GH is widely used; however, patients with acromegaly can demonstrate normal oGTT GH suppression despite elevated IGF1 levels $(27,35)$. In patients receiving non-surgical treatment of acromegaly, such as long-acting somatostatin analogues (LA-SRIFs) (36), pegvisomant (PEG-V) (37) or radiotherapy for GH-producing adenomas, $\mathrm{GH}$ values may be misleading due to highly irregular $\mathrm{GH}$ secretion pattern and flattened GH pulses (38).

The limitations (both biological and technical) of the assays used to measure GH (39) and IGF1 are well known (40), and it was stated that additional, possibly more specific and sensitive, biomarkers are desperately needed (41).

Our study has some notable limitations. The assay for aKL has been introduced only recently; therefore, knowledge of its shortcomings is limited. Additionally, the normal range for serum levels of soluble $\alpha \mathrm{KL}$ has not been established. In our laboratory, we measured soluble $\alpha \mathrm{KL}$ in the sera of 26 healthy volunteers (11 females and 15 males; mean age 39 years) as previously reported (22): $\alpha \mathrm{KL}$ (median and IQR) was 596 (506-734) pg/ml. Similar to IGF1, serum-soluble aKL also decreases with increasing age; moreover, it may be low in patients with renal failure (11), which prompted us to routinely check creatinine. In the

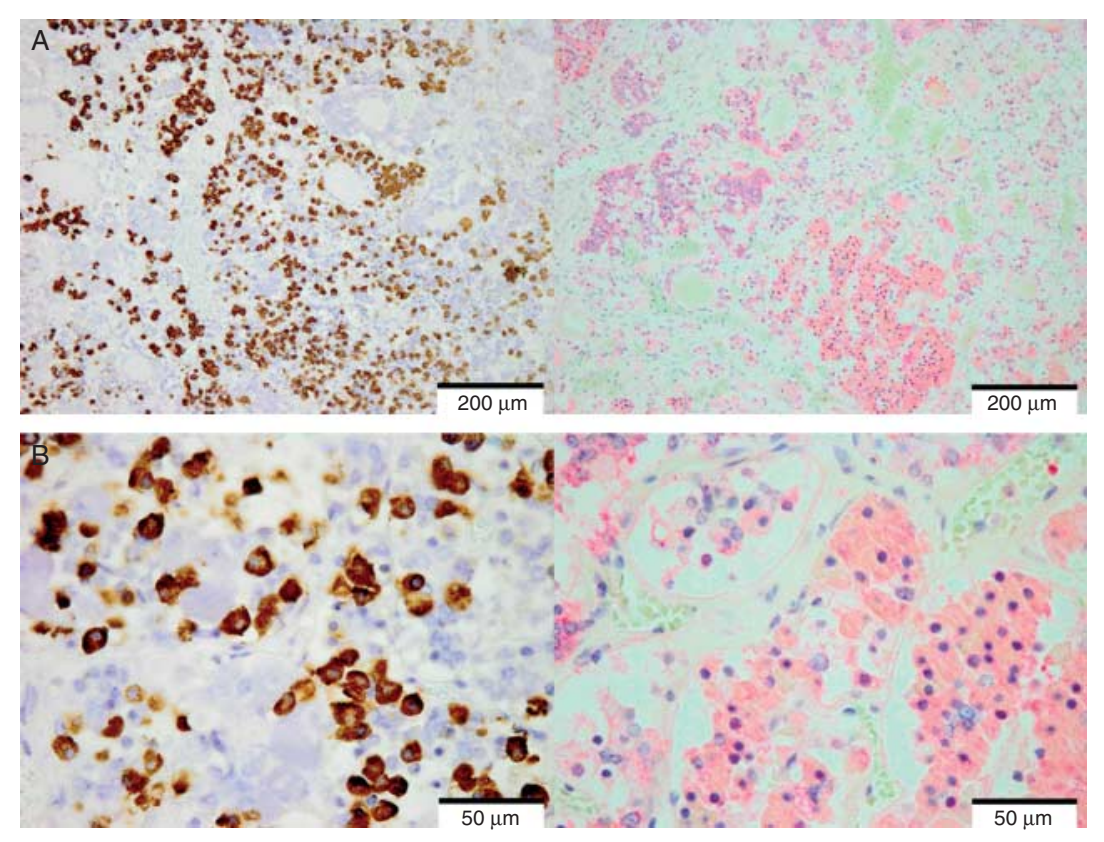

Figure 5 Expression pattern in normal pituitary. Normal pituitary shows GH positivity (brown) in the GH-producing areas. Klotho positivity (red) is observed in some lobules of normal pituitary gland, whereas other parts are negative in IHC. Original magnification $\mathrm{A}, 100 \times$ (upper panel) and $\mathrm{B}$, $400 \times$ (lower panel). 
context of NFA, some of our patients may have been GH deficient, but the design of our study did not allow us to determine whether these patients had lower than normal IGF1 and $\alpha \mathrm{KL}$ serum levels. Furthermore, the molecular mechanisms of $\alpha \mathrm{KL}$ excess in active acromegaly and the functional impact of $\alpha \mathrm{KL}$ in acromegaly disease biology remains unknown.

\section{Conclusions}

Acromegaly is (thus far, to our knowledge, up to this writing) the only acquired disease known to man with excessively elevated levels of soluble $\alpha \mathrm{KL}$. Highly elevated soluble $\alpha \mathrm{KL}$ is specific to GH-producing adenomas of the pituitary gland and rapidly decreases following adenoma removal. Thus, soluble $\alpha \mathrm{KL}$ appears to represent a new, quite specific and fairly sensitive biomarker reflecting disease activity in patients with acromegaly.

\section{Supplementary data}

This is linked to the online version of the paper at http://dx.doi.org/10. 1530/EJE-12-1045.

\section{Declaration of interest}

The authors declare that there is no conflict of interest that could be perceived as prejudicing the impartiality of the research reported.

\section{Funding}

This research did not receive any specific grant from any funding agency in the public, commercial or not-for-profit sector.

\section{References}

1 Kuro-o M, Matsumura Y, Aizawa H, Kawaguchi H, Suga T, Utsugi T, Ohyama Y, Kurabayashi M, Kaname T, Kume E et al. Mutation of the mouse klotho gene leads to a syndrome resembling ageing. Nature 1997390 45-51. (doi:10.1038/36285)

2 Kurosu H, Yamamoto M, Clark JD, Pastor JV, Nandi A, Gurnani P, McGuinness OP, Chikuda H, Yamaguchi M, Kawaguchi H et al. Suppression of aging in mice by the hormone Klotho. Science 2005 309 1829-1833. (doi:10.1126/science.1112766)

3 Arking DE, Krebsova A, Macek M Sr, Macek M Jr, Arking A, Mian IS, Fried L, Hamosh A, Dey S, McIntosh I et al. Association of human aging with a functional variant of Klotho. PNAS 200299 856-861. (doi:10.1073/pnas.022484299)

4 Ichikawa S, Imel EA, Kreiter ML, Yu X, Mackenzie DS, Sorenson AH, Goetz R, Mohammadi M, White KE \& Econs MJ. A homozygous missense mutation in human KLOTHO causes severe tumoral calcinosis. Journal of Clinical Investigation $2007 \mathbf{1 1 7}$ 2684-2691. (doi:10.1172/JCI31330)

5 Urakawa I, Yamazaki Y, Shimada T, Iijima K, Hasegawa H, Okawa K, Fujita T, Fukumoto S \& Yamashita T. Klotho converts canonical FGF receptor into a specific receptor for FGF23. Nature $2006 \mathbf{4 4 4} 770-774$. (doi:10.1038/nature05315)

6 Kurosu H, Ogawa Y, Miyoshi M, Yamamoto M, Nandi A, Rosenblatt KP, Baum MG, Schiavi S, Hu MC, Moe OW et al.
Regulation of fibroblast growth factor-23 signaling by Klotho. Journal of Biological Chemistry $2006 \quad \mathbf{2 8 1}$ 6120-6123. (doi:10.1074/jbc.C500457200)

7 Kuro-o M. Klotho and aging. Biochimica et Biophysica Acta 2009 1790 1049-1058. (doi:10.1016/j.bbagen.2009.02.005)

8 Imura A, Tsuji Y, Murata M, Maeda R, Kubota K, Iwano A, Obuse C, Togashi K, Tominaga M, Kita $\mathrm{N}$ et al. $\alpha$-Klotho as a regulator of calcium homeostasis. Science 2007316 1615-1618. (doi:10.1126/science.1135901)

9 Chen CD, Podvin S, Gillespie E, Leeman SE \& Abraham CR. Insulin stimulates the cleavage and release of the extracellular domain of Klotho by ADAM10 and ADAM17. PNAS $2007 \mathbf{1 0 4}$ 19796-19801. (doi:10.1073/pnas.0709805104)

10 Imura A, Iwano A, Tohyama O, Tsuji Y, Nozaki K, Hashimoto N, Fujimori T \& Nabeshima Y. Secreted Klotho protein in sera and CSF: implication for post-translational cleavage in release of Klotho protein from cell membrane. FEBS Letters $2004 \mathbf{5 6 5}$ 143-147. (doi:10.1016/j.febslet.2004.03.090)

11 Yamazaki Y, Imura A, Urakawa I, Shimada T, Murakami J, Aono Y, Hasegawa H, Yamashita T, Nakatani K, Saito Y et al. Establishment of sandwich ELISA for soluble $\alpha$-Klotho measurement: agedependent change of soluble $\alpha$-Klotho levels in healthy subjects. Biochemical and Biophysical Research Communications 2010398 513-518. (doi:10.1016/j.bbrc.2010.06.110)

12 Semba RD, Cappola AR, Sun K, Bandinelli S, Dalal M, Crasto C, Guralnik JM \& Ferrucci L. Plasma Klotho and mortality risk in older community-dwelling adults. Journals of Gerontology. Series A, Biological Sciences and Medical Sciences 201166 794-800. (doi:10.1093/gerona/glr058)

13 Ohata Y, Arahori H, Namba N, Kitaoka T, Hirai H, Wada K, Nakayama M, Michigami T, Imura A, Nabeshima $\mathrm{Y}$ et al. Circulating levels of soluble $\alpha$-Klotho are markedly elevated in human umbilical cord blood. Journal of Clinical Endocrinology and Metabolism 201196 E943-E947. (doi:10.1210/jc.2010-2357)

14 Siahanidou T, Garatzioti M, Lazaropoulou C, Kourlaba G, Papassotiriou I, Kino T, Imura A, Nabeshima Y \& Chrousos G. Plasma soluble $\alpha$-Klotho protein levels in premature and term neonates: correlations with growth and metabolic parameters. European Journal of Endocrinology $2012 \quad \mathbf{1 6 7} \quad 433-440$. (doi:10.1530/EJE-12-0476)

15 Holdaway IM \& Rajasoorya C. Epidemiology of acromegaly. Pituitary 19992 29-41. (doi:10.1023/A:1009965803750)

16 Dekkers OM, Biermasz NR, Pereira AM, Romijn JA \& Vandenbroucke JP. Mortality in acromegaly: a metaanalysis. Journal of Clinical Endocrinology and Metabolism 200893 61-67. (doi:10.1210/jc.2007-1191)

17 Corvilain J, Abramow M \& Bergans A. Some effects of human growth hormone on renal hemodynamics and on tubular phosphate transport in man. Journal of Clinical Investigation 196241 1230-1235. (doi:10.1172/JCI104584)

18 Lund B, Eskildsen PC, Lund B, Norman AW \& Sorensen OH. Calcium and vitamin D metabolism in acromegaly. Acta Endocrinologica $198196444-450$.

19 Takamoto S, Tsuchiya H, Onishi T, Morimoto S, Imanaka S, Mori S, Seino Y, Uozumi T \& Kumahara Y. Changes in calcium homeostasis in acromegaly treated by pituitary adenomectomy. Journal of Clinical Endocrinology and Metabolism 198561 7-11. (doi:10.1210/jcem-61-1-7)

20 Tonelli M, Sacks F, Pfeffer M, Gao Z, Curhan G \& Cholesterol and Recurrent Events Trial I . Relation between serum phosphate level and cardiovascular event rate in people with coronary disease. Circulation 2005112 2627-2633. (doi:10.1161/CIRCULATIONAHA.105.553198)

21 Foley RN. Phosphate levels and cardiovascular disease in the general population. Clinical Journal of the American Society of Nephrology 20094 1136-1139. (doi:10.2215/CJN.01660309)

22 Sze L, Bernays RL, Zwimpfer C, Wiesli P, Brandle M \& Schmid C. Excessively high soluble Klotho in patients with acromegaly. Journal of Internal Medicine 2012272 93-97. 
23 Bellut D, Hlavica M, Schmid C \& Bernays RL. Intraoperative magnetic resonance imaging-assisted transsphenoidal pituitary surgery in patients with acromegaly. Neurosurgical Focus 201029 E9. (doi:10.3171/2010.7.FOCUS10164)

24 Matsumura Y, Aizawa H, Shiraki-Iida T, Nagai R, Kuro-o M \& Nabeshima Y. Identification of the human klotho gene and its two transcripts encoding membrane and secreted klotho protein. Biochemical and Biophysical Research Communications 1998242 626-630. (doi:10.1006/bbrc.1997.8019)

25 Bloch L, Sineshchekova O, Reichenbach D, Reiss K, Saftig P, Kuro-o M \& Kaether C. Klotho is a substrate for $\alpha-, \beta-$ and $\gamma$-secretase. FEBS Letters 2009583 3221-3224. (doi:10.1016/ j.febslet.2009.09.009)

26 Saftig P \& Reiss K. The "A Disintegrin and Metalloproteases" ADAM10 and ADAM17: novel drug targets with therapeutic potential? European Journal of Cell Biology 201190 527-535. (doi:10.1016/j.ejcb.2010.11.005)

27 Giustina A, Barkan A, Casanueva FF, Cavagnini F, Frohman L, Ho K, Veldhuis J, Wass J, Von Werder K \& Melmed S. Criteria for cure of acromegaly: a consensus statement. Journal of Clinica Endocrinology and Metabolism 200085 526-529. (doi:10.1210/ jc.85.2.526)

28 Melmed S, Casanueva F, Cavagnini F, Chanson P, Frohman LA, Gaillard R, Ghigo E, Ho K, Jaquet P, Kleinberg D et al. Consensus statement: medical management of acromegaly. European Journal of Endocrinology 2005153 737-740. (doi:10.1530/eje. 1.02036)

29 Melmed S, Colao A, Barkan A, Molitch M, Grossman AB, Kleinberg D, Clemmons D, Chanson P, Laws E, Schlechte J et al. Guidelines for acromegaly management: an update. Journal of Clinical Endocrinology and Metabolism 200994 1509-1517. (doi:10.1210/jc.2008-2421)

30 Zapf J. Physiological role of the insulin-like growth factor binding proteins. European Journal of Endocrinology 1995132 645-654. (doi:10.1530/eje.0.1320645)

31 Ranke MB \& Elmlinger M. Functional role of insulin-like growth factor binding proteins. Hormone Research $1997 \mathbf{4 8}$ (Suppl 4) 9-15. (doi:10.1159/000191304)

32 Clemmons DR. IGF-I assays: current assay methodologies and their limitations. Pituitary 200710 121-128. (doi:10.1007/ s11102-007-0032-z)

33 Zapf J, Morell B, Walter H, Laron Z \& Froesch ER. Serum levels of insulin-like growth factor (IGF) and its carrier protein in various metabolic disorders. Acta Endocrinologica 198095 505-517.

34 Zapf J, Walter H \& Froesch ER. Radioimmunological determination of insulinlike growth factors I and II in normal subjects and in patients with growth disorders and extrapancreatic tumor hypoglycemia. Journal of Clinical Investigation 198168 1321-1330. (doi:10.1172/JCI110379)

35 Subbarayan S, Fleseriu M, Gordon M, Brzana J, Kennedy L, Faiman C, Hatipoglu B, Prayson RA, Delashaw JB, Weil RJ et al. Serum IGF-1 in the diagnosis of acromegaly and the profile of patients with elevated IGF-1 but normal glucose-suppressed growth hormone. Endocrine Practice 201218 817-825. (doi:10.4158/ EP11324.OR)

36 Arafat AM, Mohlig M, Weickert MO, Perschel FH, Purschwitz J, Spranger J, Strasburger CJ, Schofl C \& Pfeiffer AF. Growth hormone response during oral glucose tolerance test: the impact of assay method on the estimation of reference values in patients with acromegaly and in healthy controls, and the role of gender, age, and body mass index. Journal of Clinical Endocrinology and Metabolism 200893 1254-1262. (doi:10.1210/jc.20072084)

37 Trainer PJ, Drake WM, Katznelson L, Freda PU, Herman-Bonert V, van der Lely AJ, Dimaraki EV, Stewart PM, Friend KE, Vance ML et al. Treatment of acromegaly with the growth hormone-receptor antagonist pegvisomant. New England Journal of Medicine 2000 342 1171-1177. (doi:10.1056/NEJM200004203421604)

38 van der Klaauw AA, Pereira AM, van Thiel SW, Frolich M, Iranmanesh A, Veldhuis JD, Roelfsema F \& Romijn JA. Attenuated pulse size, disorderly growth hormone and prolactin secretion with preserved nyctohemeral rhythm distinguish irradiated from surgically treated acromegaly patients. Clinical Endocrinology 200766 489-498. (doi:10.1111/j.1365-2265.2006.02757.x)

39 Bidlingmaier M \& Strasburger CJ. Growth hormone assays: current methodologies and their limitations. Pituitary 200710 115-119. (doi:10.1007/s11102-007-0030-1)

40 Clemmons DR. Consensus statement on the standardization and evaluation of growth hormone and insulin-like growth factor assays. Clinical Chemistry 201157 555-559. (doi:10.1373/ clinchem.2010.150631)

41 Neggers SJ, Biermasz NR \& van der Lely AJ. What is active acromegaly and which parameters do we have? Clinical Endocrinology 201276 609-614. (doi:10.1111/j.1365-2265.2012. 04346.x)

Received 29 November 2012

Revised version received 18 January 2013

Accepted 29 January 2013 